\title{
Association of MDR1 gene C3435T (rs1045642) polymorphism with colorectal cancer in the population of Central Russia
}

\author{
A.S. Moskalev, E.M. Barysheva, O.Yu. Bushueva* \\ Kursk State Medical University, Kursk, Russia \\ e-mail: olga.bushueva@inbox.ru
}

Key words: colorectal cancer, $M D R 1$ gene, SNP

Motivation and Aim: Colorectal cancer (CRC) is one of the most common cancers worldwide. Currently, the incidence of $\mathrm{CRC}$ tends to increase. Genetic factors together with environmental factors might increase the risk of colorectal cancer [1]. It is well known that genes encoding drugs metabolism enzymes are involved in the pathogenesis of colorectal cancer. The multidrug resistance gene 1 (MDR1, ATP binding cassette subfamily B member 1, ABCB1) encodes a transmembrane glycoprotein $\mathrm{P}$, involved in the transformation of drugs. Recent studies indicated MDR1 gene seemed to play an important role in tumor progression, especially in the colorectal carcinogenesis [2].

Methods and Algorithms: A total 379 unrelated Russian subjects including 244 CRC patients and 135 age- and sex-matched controls were recruited for this study. Genomic DNA was isolated from peripheral blood samples using a standard phenol/chloroform procedure. Genotyping of the 3435C $>$ T polymorphism (rs1045642) of the MDR1 gene was done using TaqMan-based assay on the CFX96 real-time PCR Detection System. Hardy-Weinberg equilibrium was tested to compare the observed and expected genotype frequencies among cases and controls using chi-square test. The association between the polymorphism and CRC risk was estimated by odds ratio (OR) with $95 \%$ confidence interval (CI). The statistical significance was established at $\mathrm{P}<0,05$. Statistical calculations were performed with Statistica for Windows 8.0.

Results: The MDR1 genotype frequencies were in agreement with Hardy-Weinberg equilibrium in $\mathrm{CRC}$ and control groups $(\mathrm{P}>0,05)$, which indicates uniformity of the sample. The frequency of homozygous genotype $3435 \mathrm{CC}$ was $22,1 \%$ in patients and $33,3 \%$ in healthy controls. The frequency of heterozygous genotype $3435 \mathrm{CT}$ was 50,4 and $47,4 \%$ in patients and controls, respectively. Homozygous genotype 3435TT was observed in $27,5 \%$ of cancer patients and in $19,3 \%$ of healthy individuals. Thus, we have established that homozygous genotype $3435 \mathrm{CC}$ of the MDRl was associated with protective effect against the risk of $\mathrm{CRC}(\mathrm{OR}=0,57 ; 95 \% \mathrm{CI}=0,36-0,91 ; \mathrm{P}=0,02)$.

Conclusion: In conclusion, our study showed that MDR1 C3435T polymorphism might be significantly associated with risk of CRC in the population of Central Russia. Further studies, especially the gene-gene and gene-environment interactions are required.

\section{References}

1. Grady W.M., Carethers J.M. (2008). Genomic and epigenetic instability in colorectal cancer pathogenesis. Gastroenterol. 135(4):1079-1099.

2. Chin J.E., Soffir R.E.N.A., Noonan K.E., Choi K. Y. U. N. G. H. E. E., Roninson I.B. (1989). Structure and expression of the human MDR (P-glycoprotein) gene family. Mol. Cell. Biol. 9(9):3808-3820. 